\title{
Win, Lose or Draw? The Fate of Patented Inventions
}

\author{
John P. Walsh \\ jpwalsh@gatech.edu \\ Georgia Institute of Technology, USA \\ You-Na Lee \\ Georgia Institute of Technology, USA \\ Taehyun Jung \\ Hanyang University, Korea
}

\begin{abstract}
Using information from a survey of US inventors, this study explores the reasons for patent nonuse and different types of non-use at the patent level, and how this varies by industry and firm characteristics. We find that $55 \%$ of triadic patents are commercialized. We also find that $17 \%$ of all triadic patents are not commercialized but are at least partially for preemption, though only $3 \%$ of all triadic patents are purely preemptive patents. We find that preemptive non-use is less common than failed patents. We then test the discriminating effects of patent effectiveness, competition, firm size and fragmentation of patent rights on the likelihood of preemptive patents. We find that greater patent effectiveness, more competition, and large firm size are associated with greater preemptive non-use relative to commercial use of patents. We discuss the policy implications of our results.
\end{abstract}

Key words: patent non-use, preemptive patents, patent policy, US economy

Acknowledgements: We would like to thank Research Institute for Economics, Trade and Industry, the Georgia Research Alliance and the National Science Foundation (NSF0823372 and NSF1261418)for funding for this project. We also thank participants in the $5^{\text {th }}$ EPIP Conference, Maastricht and the Conference on Patent Use, London, and the anonymous reviewers for helpful comments. 


\section{Win, Lose or Draw? The Fate of Patented Inventions}

\section{Introduction}

Considering the exclusive right to invention as given not of natural right, but for the benefit of society, I know well the difficulty of drawing a line between the things which are worth to the public the embarrassment of an exclusive patent, and those which are not. Thomas Jefferson (1813)

Patents are designed to promote science and the useful arts by giving the owner exclusive rights over an invention for a limited period of time (see, for example, U.S. Constitution, Art. I, sec. 8).Firms are typically seen to exercise this right by using the technology in their own products and using the patent to enforce market exclusivity, or through licensing to others in exchange for a share of the rents. However, over the last two decades we have seen a growth in patenting and an increasing emphasis on preemptive (sometimes called "strategic") non-use of patents to build fences around a technology or to prevent others from patenting and suing the focal firm (thereby ensuring freedom to operate, sometimes formalized through cross-licensing). Using patents to enhance strategic advantage in the competitive landscape is not a recent phenomenon (Merges, 1994; Saunders, 2001; Turner, 1998). However, as technology has become more critical for the competitiveness of contemporary firms (Baumol, 2002; Jaffe, 2000) and patent filings have exploded(Kortum and Lerner, 1999; Shapiro, 2001; van Zeebroeck et al., 2008), both managers and management theorists have begun to re-examine the uses of patents (Blind et al., 2006; Cohen et al., 2000; Giuri et al., 2007; Hall and Ziedonis, 2001; Rivette and Kline, 2000; Sheehan et al., 2004). Some argue that this preemptive (or strategic) non-use is key to a well-founded firm strategy (Ziedonis, 2004), while others argue that such non-use is evidence of a broken patent system (Heller and Eisenberg, 1998; Jaffe and Lerner, 2004; Shapiro, 2001).

The law has not responded well to the problem of non-use of patents. Since the 1908 Continental Paper Bag Supreme Court ruling, the non-use or refusal to license patent rights has generally been seen as an allowable exercise of the government-granted patent right (Saunders, 2001). ${ }^{1}$ US patent law specifically allows for patent non-use. Section 271(d)(4) of the Patent Act states that "No patent owner otherwise entitled to relief for infringement... shall be denied relief or deemed guilty of misuse or illegal extension of the patent right by reason of having....refused to license or use any rights to the patent." Thus, non-use of patents is codified in US patent law. However, such preemptive patent non-use has long been controversial. As Justice Douglas wrote in dissent in Special Equipment Co. v. Coe (1945): "One patent is used merely to protect another... It is difficult to see how that use of patents can be reconciled with the purpose of the Constitution 'to promote the progress of science and the useful arts'."

In addition to preemptive non-use, patent non-use can result from a variety of other causes,

\footnotetext{
${ }^{1}$ For a discussion of the relation between antitrust policy and patent policy, see Lemley (2011) and US Department of Justice \& Federal Trade Commission (2007).
} 
including the low value of the invention and rapid technological change making the invention not economical to commercialize. This line of argument motivates the following research questions: how common are non-use patents, what are the different types of non-use, and how do these different types of non-use vary by firm and environmental characteristics?

There have been several recent empirical studies on motives to patent (Blind et al., 2006; Cohen et al., 2000; Giuri et al., 2007). These studies find that so-called "strategic" non-uses of patents are important motives, such as patents to prevent rivals from inventing around a focal patent or to prevent rivals from getting a patent that would reduce the focal firm's freedom to operate (Cohen et al., 2000; Gharrity, 1966).We shall refer to these uses as "preemptive" nonuse of patents. ${ }^{2}$ Cohen et al. (2000)suggest preemptive non-use of patents may contribute to firms' incentives to conduct R\&D beyond the effects of patents for preventing copying or for licensing.Hall and Ziedonis (2001) andKortum and Lerner (1999)argue the growth in patenting is in part driven by the proliferation of preemptive patenting, although getting a good estimate of the rate of preemptive patenting has proven difficult. Giuri et al. (2007) report that $19 \%$ of European patents are not used and are patented for strategic blocking (accounting for about half of all non-use patents) and 3\% are used for cross-licensing, with blocking patents most common in the chemicals and drugs sector. Motohashi (2008) reports that 33\% of all Japanese patents are reported to be either for blocking or unused for other reasons, with cross-licensing accounting for about $9 \%$ of all patents (Motohashi, 2008). Thus, patent-level data from Japan and Europe suggest that preemptive patenting is quite common, accounting for a significant share of non-use patents, although the exact rates vary by definition and context.Much of this work uses surveys on reasons to patent. ${ }^{3}$ However, a priori motivations for patenting may not be maintained as the potential of the patented technology and of related technologies becomes clearer.

Therefore, the main contributions of this paper are that we examine the fate of each patent (used or not), and the different reasons for non-use of patents (after the firm has had time to establish use or non-use). In particular, we estimate the share of preemptive patents, among patents that are not commercially used, regardless of the initial motivation associated with the patenting. In other words, our interest is "patent non-use for preemptive reasons", not "patents applied for for preemptive reasons". Furthermore, we compare preemptive patents to commercial patents to see how firm and environmental characteristics affect the rates of preemptive non-use of patents.

The structure of this paper is as follows. We first describe our main dataset. Second, we compare motivations for patenting to actual use of patents to motivate our operationalization of non-use patents, and then examine statistics on different reasons for patent non-use and create a typology of non-use patents. Third, we provide some exploratory analyses to compare

\footnotetext{
${ }^{2}$ We adopt the term "preemptive" from Gilbert and Newbery (1982).

${ }^{3}$ Motohashi (2008) is an exception.Although Giuri, et al. (2007) and Torrisi et al. (2015) combine data on reasons for patenting (e.g., blocking or not) and data on commercialization to measure their rate of (supposed) strategic non-use, they do not have data on ex post reasons for non-use of patented inventions to measure the (consequent) preemptive non-use.
} 
preemptive non-use to commercial use of patents. Lastly, we conclude with results and implications.

\section{Data on US inventions}

We make use of a US inventor survey(Walsh et al., 2015; Walsh and Nagaoka, 2009). For the survey, we drew a systematic random sample of 9060 (out of 32,390) triadic patents (that had been applied for at the EPO and JPO and granted by the USPTO) with at least one US-addressed inventor and priority years from 2000 to 2003, stratified by NBER technology class. Taking the first available US inventor as the representative inventor, and after randomly drawing one patent for inventors with multiple patents in our sample, we have 7,933 unique US-based inventors in our mail-out sample. After sending the survey packet (with first-class stamps and individualized, signed cover letters), follow-up letters and a second-wave mailing of the full packet (Dillman, 2007), we received 1919 responses (24\%). After excluding undeliverable, deceased, etc., from the denominator, we have an adjusted response rate of $32 \%$. A detailed non-response bias analysis shows little evidence of non-response biases that were either statistically or substantively significant. ${ }^{4}$ For this study, we limit our sample to responses from inventors working in firms, leading to 1739 cases.

Triadic patents are a subset of US patents, over-representing those that may have significant value (enough to take on the expense of filing in three jurisdictions) and a potential global market. Thus, this population may underestimate the rate of preemptive patents.By comparing rates of preemptive non-use to other forms of non-use, we can to some extent control for this limitation in our sample.Still, it is important to note that the overall rates of non-use patents compared to commercially used patents may be lower in our sample than in some prior samples drawn from the general population of patented inventions. There may also be concerns that our sample over-represents large firms. However, a detailed comparison of the firms in our sample shows that the firm size distribution in our sample is not significantly different from the

\footnotetext{
${ }^{4}$ Comparing respondents and non-respondents based on bibliometric indicators revealed few differences that were either statistically or substantively significant.In particular, measures of collaboration (solo inventions: $27 \%$ for respondents, $26 \%$ for non-respondents; average number of inventors: 2.71 for respondents, 2.80 for non-respondents), links to universities (citations to non-patent literature: 2.4 for respondents v.2.7 for non-respondents) and measures of patent value (forward citations: 2.2 for respondents and 2.4 for non-respondents) are all similar (none are significantly different, $\mathrm{p}<.05, \mathrm{~N}=7933$ ). The only significant differences are that inventors for which we only had a company address (instead of home address) are less likely to respond (4\% of respondents had a company address v. $6 \%$ for nonrespondents, $\mathrm{p}<.001$ ) and those with more patents in our sample are more likely to respond (mean of 1.18 patents for respondents, 1.13 for non-respondents, $\mathrm{p}<.001$ ), although the absolute differences are quite small.Thus, despite the modest response rate, we have some confidence that our sample is representative of the underlying population of US-based inventors on triadic patents.

In addition, this survey used a stratified sample with equal probability, except for multi-invention inventors. The number of patents belonging to each unique inventor was recorded to use as a weight to check the effect of the weight. However, comparing statistics with weights and without weights, we found that the weights have very minimal influence in this study and hence were not applied (for more information, see Jung, 2009).
} 
underlying population of innovating firms (Jung, 2009). In particular, there are a substantial number of patents from small and medium firms in our sample (about $20 \%$ of the sample of patents come from firms with less than 500 employees).

\section{Non-use of patents}

One novel aspect of our survey is that, in addition to asking the reasons for applying for the patent (as was done in Cohen et al., 2000; Blind et al., 2009; Giuri et al., 2007, and Torrisi et al., 2015), we asked for the reasons for non-use of patents that were not commercialized(after patenting). This measure of reasons for non-use is our main focus, allowing us to estimate the actual rates of different forms of non-use of patents, regardless of the initial motivation or reason for patenting. ${ }^{5}$ Prior work notes the difficulties of estimating rates of patent use, due to differences in definitions of use or non-use (Gharrity, 1966; Saunders, 2001).In particular, nonuse patents may have the "use" of protecting other patented inventions that are commercialized, for example, by preventing rivals from inventing around.We will say that a patent is "used" commercially if it covers a product that the firm sells, or a process that is used in making a product that the firm sells, or the patent is licensed to another firm, or the patent has been used as the basis for starting a new firm (cf. Gharrity, 1966). ${ }^{6}$

We first examine to what extent motives for patenting are linked to outcomes. Table 1 shows what share of patents with commercial and preemptive motives were actually commercialized. For motive to patent, the survey asked "how important were the following reasons for patenting this invention at the time of the invention? $(1=$ not important to $5=$ very important)." We define the items: "Commercial exploitation (to obtain exclusive rights to exploit the invention economically)" and "Licensing (to obtain exclusive rights to license the invention in order to generate licensing revenues)", as commercial motive, and the items: "Pure defense (to ensure that the use of your own technology not be blocked by others)", "Blocking patents (preventing others from patenting similar inventions, complements or substitutes)" and "Preventing inventing-around other key patents of your firm" as preemptive motive (cf. Cohen et al., 2000; Blind et al., 2007; Giuri et al., 2007). If the union of items for commercial motive has the maximum value, 5 (= very important), commercial motive is coded as high and if it has lower values (1 to 4), commercial motive is coded as low. In the same way, if the union of items for preemptive motive has the maximum value 5, preemptive motive is high and otherwise low.

Table 1 shows that among patents that have high commercial motive at the time of

\footnotetext{
${ }^{5}$ The European surveys (PatVal1 and PatVal2) by Guiri et al. (2007) and Torrisi et al. (2015) do not include the question asking reasons for non-use of patents. Also see footnote 3.

${ }^{6} \mathrm{We}$ measured commercial use with the following three item: "Has the applicant/owner ever used the patented invention in a product/process/service that has been commercialized?"; "Has the focal patent been licensed by (one of) the patent-holder(s) to an independent party?"; and "Has this patent been exploited commercially by yourself or any of your co-inventors for starting a new company?"If the respondent said "Yes" to any of these items, then this is a commercially used patent.Otherwise, it is a non-use patent.
} 
invention, 39.8\% were actually not commercialized. Out of patents that have high preemptivemotive at the time of invention, 58.9\% were commercially used, which shows that it is common that patents that were judged to have largely a preemptive motive at the time of invention did not stay that way. ${ }^{7}$ Note that this question is asked of the inventor after the fact (several years after the patent was applied for), and when the outcome of the patent (use or nonuse) was better known.Hence, this method is likely to over-estimate the linkage between motive and outcome, which suggests that this is a conservative estimate of the degree of mismatch. Furthermore, Table 1 shows that it is common for the same patent to have both a preemptive motive and a commercial motive.Out of patents that have high preemptive motive at the time of invention, $72 \%$ also have commercial motive. Looking beyond motives and into the reasons for non-use of patents that were not commercialized should, therefore, be valuable.

\section{--INSERT TABLE 1 ABOUT HERE--}

\subsection{Reasons for non-use of patents and types of non-use patents}

To estimate rates of use and non-use of patents and reasons for non-use if not used, we, first, asked respondents if the patent was commercialized either in-house, by licensing, or through a startup (non-exclusive questions) (see footnote 6). Then, if the patent was not commercialized, we ask why it was not used, with the respondent allowed to check more than one reason. We have 1618 cases that clearly indicate whether or not the patent was used, of which 721 patents $(45 \%)$ were not used at the time of the survey (4 to 7 years after application). In addition, the commercial use patents ( $55 \%$ of the total) includes $3 \%$ that were used for cross-licensing. Our finding of $55 \%$ of triadic patents being commercially used is similar to that found in Torrisi, et al. (2015). ${ }^{8}$ Out of 721 patents that were not commercialized, 625 cases provide reasons for non-use and so are employed for the statistics in Figure 1. The most common reason is that the firm was still exploring the commercial possibilities of the invention ( $48 \%$ of non-use patents). However, $30 \%$ of non-use patents are due to changes in technology or market environment reducing the value of the invention. Other reasons for non-use include obsolescence, lack of capital or lack of application or complementary technology.

A significant share of non-commercialized patents is used for preemption, with $34 \%$ for "Blocking other firms" and 23\% for "Preventing inventing-around." As these statistics show,

\footnotetext{
${ }^{7}$ Note that our definition of commercial use includes licensing that is part of a cross-licensing deal, which may be considered as a type of "preemptive" use (cf. Cohen et al., 2000; Giuri et al. 2007; Motohashi 2008). If we exclude use for cross-licensing from "commercial use", then $58.1 \%$ of patents filed for preemptive motives are commercially used.

${ }^{8}$ In the recent PatVal2 survey of patent applications filed at the European Patent Office (EPO), Torrisi et al. (2015) describe the following uses of patents: commercial (in-house) use, sale, licensing, starting new firm. This set of uses roughly corresponds to our "commercialized" patents (we did not include "sales", which Torris et al. note are fairly rare). They find that $58 \%$ of the multi-nation sample of EPO patent applications were used in one or more of these ways. For their US sample, they find $61 \%$ of patent applications are "used" for one of these commercial purposes, including $2 \%$ for cross-licensing.
} 
firms use patents to prevent other firms from introducing rival technologies (Blind et al., 2009; Lemley and Shapiro, 2005). For example, in the 1940s, du Pont patented over 200 substitutes for Nylon to protect its core invention (Hounshell and Smith, 1988). Key Supreme Court cases, including Continental Paper Bag v. Eastern Paper (1908) and Special Equipment Co. v. Coe (1945), legitimated such uses in US law (Saunders, 2001). Also, firms acquire non-use patents to show the ability to counter-sue in order to prevent any rival from filing suit to exclude the focal firm (Allison et al., 2009). In this case, the patents are used not necessarily to keep rivals out, but to ensure that the focal firm can participate in the market (freedom to operate). This freedom to operate is often cemented by a cross-licensing agreement, a kind of peace treaty ensuring each firm access to the market (Grindley and Teece, 1997; Hall and Ziedonis, 2001). The classic case is large electronics firms cross-licensing their patent portfolios related to computers, cell phones or semiconductors, and then each competing on lead time, manufacturing capabilities, or marketing.

\section{--INSERT FIGURE 1 ABOUT HERE--}

These reasons for patent non-use can be grouped by whether the patent still has a potential value for the firm, whether the patented technology failed in terms of market or technical potential and whether the patent is primarily preemptive. Table 2 shows our typology of non-use patents based on reasons for non-use. We define the cases of technology and market obsolescence and low value of invention as failed patents. We define patents not yet commercialized but still possibly able to be commercialized ("Still exploring the commercial possibility", "Used internally as a research tool to develop other commercial technologies", "Lack of application technology for this basic invention" and "Development of complementary technology delayed") as prospective patents. Finally, we define those non-use patents used for maintaining monopoly or bargaining power over potential competitors ("Blocking other firms" and "Preventing inventing-around") as preemptive patents (see Appendix A). The bottom of Figure 1 displays the rates of different types of non-use patents.Non-use patents are primarily prospective or failed rather than preemptive. ${ }^{9}$ Respondents were allowed to provide multiple reasons, so these three categories are not exclusive.

\section{--INSERT TABLE 2 ABOUT HERE--}

Figure 2 shows that some non-use patents have ambivalent or multi-faceted characteristics, not exclusively prospective, preemptive or failed. Thus, it is important to understand that patents can serve multiple functions simultaneously, which may vary as market and technology conditions

\footnotetext{
${ }^{9}$ One could consider "Lack of application technologies for this basic invention" and "Development of complementary technology delayed" as "failed" patents.Reclassifying these two categories, prospective would decrease to $56 \%$ and failed would increase to $66 \%$, but both would still be more common than preemptive.
} 
vary over the life of the patent. The firm may be exploring the commercial possibilities of a patented technology, while simultaneously holding the patent for preemptive purposes. Also, although the line of business is being downsized, the firm may explore the commercial use of the invention in different industries or use it for preemption in a different market. About $54 \%$ of non-use patents fitmultipletypes. However, $23 \%$ of non-use patents are exclusively prospective, $18 \%$ exclusively failed and $6 \%$ exclusively preemptive. Even for exclusive cases, the rate of preemptive patentsis lower than those of prospective and failed patents.Put differently, for $82 \%$ of the non-use patents where use is not still being considered, the reason for non-use was at least in part a change in technology or market conditions (failed non-use).

For comparison, Gharrity (1966) reports on two other prior studies (both from the mid-20 $0^{\text {th }}$ century) that also asked inventors or firms whether a given patent was used or not and if not, why. One study, by Sanders et al., based on a broad sample of US patents found that of the nonuse patents (excluding those where use was still intended), over $80 \%$ were failed patents.Similarly, data from an internal audit of over 9000 AT\&T patents from the 1930s shows that almost half had been commercialized, and, of the non-use patents, $30 \%$ were prospective patents, and about 70\% were failed patents. Thus, Gharrity (1966) concludes preemptive patentsare rare.

Depending on how we treat multiple reasons, our conclusions may vary somewhat.If we include all patents that are at least partially used for preemption, we find almost $40 \%$ of non-use patents (17\% of all triadic patents) are for preemption.However, many of these are also prospective or failed patents (Figure 1).If we limit our definition to those that are exclusively preemptive, we find only $6 \%$ of non-use patents (or $3 \%$ of all triadic patents) are preemptive (Figure 2).Using the second definition, our results suggest that, like estimates of patent use and non-use from the last century, preemptive patents are uncommon. If we take the broader definition, the results suggest that, while less common than prospective or failed patents, preemptive patents account for a significant share of inventions.

If this preemptive non-use helps the firm secure temporary monopoly power or have a better negotiation position, it may be seen as an effective way to use patents. If such preemptive non-use causes the problem of technology suppression, it may have adverse effects on social welfare, even though such use may be consistent with patent law (Saunders, 2001). And, such use may even be critical for promoting dynamic efficiency, even in the face of static deadweight loss, to the extent that preemptive non-use helps provide the appropriability needed to give firms incentives to invest in initial and follow-on innovation. Also, as Saunders (2001) argues, preemptive non-use per se may not be anticompetitive unless it creates monopoly power in the relevant market, as control over a technology may not map onto monopoly power in a particular product market, which may contain multiple competing technologies. Various drugs of the same class is a classic case. Moreover, if patent non-use per se is a problem in the current patent system, Figure 2 indicates that failed patents, rather than preemptive patents, may be the bigger problem. 


\section{--INSERT FIGURE 2 ABOUT HERE-}

\subsection{Variation in the rates of the three types of non-use}

The rates of different types of non-use of patents should vary by industry, technology or firm as motivation for and effectiveness of patents is different across industries or technologies (Cohen et al., 2000). We compare these rates across product industry, speed of technology progress and firm size. Table 3 shows the rates of prospective, preemptive and failed patents by product industry with both non-exclusive statistics (labeled any) and exclusive statistics (labeled pure). Because the use or non-use of patents is closely related to characteristics of the industry thatthe patent is directly related to(Cohen et al., 2000) (i.e., the industry of the patent, not the firm), we link the primary US patent class of patents in our sample to their product industry using the USPTO US patent class-product industry NAICS concordance. ${ }^{10}$ For our non-exclusive measures, we find significant industry differences for prospective and preemptive patents, but not for failed patents. For our exclusive measures, we find a significant difference for failed patents, but not for the other types of non-use. We find that Pharmaceuticals (3254), Plastics and rubber products (326) and Fabricated metal products (332) are above average for both any and pure prospective patents (which is consistent with long development times in, for example, pharmaceuticals). For preemptive patents, Chemicals (325) has ahighrate of any preemptive non-use (thoughnot pure preemptive non-use), while Computers (334) and Semiconductors (3344) show high rates of pure preemptive non-use (but not any preemptive non-use). Transportation equipment (336) is also high on preemptive non-use of patents. These include industries where patents have been shown to be important for preventing rivals from inventing around the patent and/or for acquiring patents to ensure freedom to operate (Cohen et al., 2000; Hall and Ziedonis, 2001). For failed patents, Computers (334), Semiconductors (3344) and Electrical equipment (335) have high rates of failed patents, for both any and pure measures. The rapid change of technology or market in these industries may be related to these high rates of failed patents (Gharrity, 1966). Thus, like prior work, we find reasons for non-use of patents often vary by industry.

We also compared rates of each type of non-use between fast-moving and slow-moving industries. Using data from the Carnegie Mellon Survey (Cohen et al., 2000), we estimated how quickly a competitor enters the market after an innovation. ${ }^{11} \mathrm{We}$ find that the rates of failed

\footnotetext{
${ }^{10} \mathrm{~A}$ firm can produce multiple inventions associated with different industries. Therefore, considering the invention's product industry is preferable to using an assignee firm's NAICS to represent the invention's industry. Some patent classes have multiple relevant product industries in the USPTO US patent classproduct industry NAICS concordance. In this case, we randomly sample one industry. However, in our sample, over $70 \%$ of patents map to one industry in the concordance.

${ }^{11}$ The Carnegie Mellon Survey (Cohen et al., 2000) asked: "For your most significant product innovation introduced over the last ten years which you did patent, approximately how long was it until another firm introduced a competing alternative?" Answers were on a five-point scale ranging from 1:less than 6 months to 5: over 5 years.Industry means were constructed by first reverse coding (so it measures speed of imitation, rather than delay) and then taking the mean of this 1 to 5 scale. We then split industries into those where speed of competitors entering was above the overall mean (fast moving industries) and equal to or below the mean (slow moving industries).
} 
patents are significantly higher in fast moving than in slow moving industries $(59 \% \mathrm{v} .50 \%$ for any fail and $23 \% \mathrm{v} .12 \%$ for pure fail). We find rates of prospective patents are higher in slowmoving industries ( $73 \%$ v. $63 \%$ for any prospective, although no difference for pure prospective). Finally, preemptive non-useis more common in slow moving industries (45\% v. 34\%, although for pure preemptive there is no difference). Preemptive non-usemay make less sense in a fastmoving industry, because there is less need to protect a focal invention as it too is likely to become quickly obsolete. Thus, the shorter the lag time in an industry, the more respondents report the focal patent was not used because it is a failed patent and the less it is likely to be a prospective or preemptive patent.

We also compare different types of non-use patents across firm size. Prospective patents are more commonamong small firms $(75 \% \mathrm{v} .66 \%)$. Rates of preemptive patents are higher among large firms (41\% v. 24\%) (Blind et al., 2006; de Rassenfosse, 2012).For exclusivemeasures, the differences are not significant. Large firms have larger and maybe also more diversified markets than small firms so that using non-commercialized patents for preemptive purpose would create more value than for small firms (because the preemptive patent is protecting a larger revenue commercial product and/or can be protective of commercialized products in multiple markets).

Thus, there are important differences in industry and firm characteristics associated with patent non-use. In particular, preemptive non-use of patents shows significant differences by industry and by firm size. In the next section, we further explore the potential covariatesof preemptive non-use of patents.

--INSERT TABLE 3 ABOUT HERE--

\section{Exploratory analyses: drivers of preemptive non-use vs. commercial use}

In this section, we explore the determinants of preemptive patents. The existing literature has discussed when firms use patents for preemption (Blind et al., 2006; Cohen et al., 2002; Hall and Ziedonis, 2001), when firms license patents(Arora and Ceccagnoli, 2006; Gans et al., 2008), or when firms have higher incentives to patent(Cohen et al., 2000; Levin et al., 1987), each as a separate study. However, here, we further investigate when firms are more likely to have preemptive patents over commercial patents based on theories used in prior research.

\subsection{Predictors of preemptive non-use}

\subsubsection{Industry differences in patent effectiveness}

The effectiveness of patents in protecting inventions varies substantially across industries (Cohen et al., 2000; Levin et al., 1987). Because greater patent effectiveness reduces the uncertainty involved in technology markets, stronger patents may be associated with greater use of patents for commercial use, especially for licensing (Arora and Ceccagnoli, 2006; Gans et al., 2008). Moreover, producing new products or building new processes with patented technology may 
require new capital equipment, training and further research and development and strong protection by patents may be necessary to secure sufficient exclusivity time to test technology and market options and develop its final product (Bloom and Van Reenen, 2002). Thus, stronger patent effectiveness reduces market uncertainty, increasing licensing activity and drives more R\&D investment for commercial development (Bloom and Van Reenen, 2002; Czarnitzki and Toole, 2011).

On the other hand, greater patent effectiveness raises the payoff from securing patents and thereby, the preemption threat becomes a rational strategy, leading to patent races and patenting substitute products to preempt potential competitors (Gilbert and Newbery, 1982; Giuri et al., 2007). Moreover, while effective patents should obviate the need for patenting inventions surrounding the focal invention (since the single patent should protect the focal invention), stronger patents might also encourage fencing around the focal invention, since they would also be more effective at preventing rivals from inventing around (Cohen et al., 2000).These stronger fences may also encourage firms to patent complementary technologies to either gain access to rival technology through cross-licensing or to exploit the patent through the threat of a countersuit, which breaks down rivals' technology monopolies and ensures freedom to operate (Allison et al., 2009; Cohen et al., 2000; Rivette and Kline, 2000).Therefore, stronger patents might cause an acceleration of patenting "arms races", as rivals propagate their patent portfolios attempting to both build fences and ensure freedom to operate for themselves (Hall and Ziedonis, 2001).

However, the size of theimpacton these different types of use may differ by how effective other appropriability mechanisms are for securing commercialization and preemption. Strong patent protection can reduce the sellers' concerns about losing their exclusivity and encourage commercialization (Anand and Khanna, 2000; Arora and Gambardella, 2010). Patents, however, are often used with other mechanisms such as secrecy, lead-time and long-period contracts to secure appropriability, in particular, if the technology includes know-how (Anton and Yao, 2004; Arundel, 2001; Hall et al., 2012). Therefore, even though patent effectiveness is strong, if the firm is concerned about making the invention information public or revealing their know-how, they can depend more on or combine with other appropriability mechanisms to protect their invention after commercialization (Fischer and Henkel, 2013). Even with weak patent effectiveness, they can still commercialize their invention, using other appropriability mechanisms such as secrecy. However, secrecy does not preempt potential rivals. Therefore, although patent effectiveness is important to both commercialization and preemption, its effect may be relatively weaker on commercialization relative to preemption, which is to say that the probabilityof preemptive non-use to commercial use should increase as patent strength increases (even though patent strength affects each positively).

If patents are more effective, do they raise or lower the rates of preemptive non-use?This question is critical to the policy debates about patent reform. There is significant concern that patents may be overly strong and that there is too much preemptive non-use of patents, and that patent reform is needed to address this problem (Bessen and Meurer, 2008; Jaffe and Lerner, 2004). To examine this debate empirically, we test the impact of patent effectiveness on the 
probability of preemptive non-use over commercial use of patents. We measure patent effectiveness using the Carnegie Mellon Survey (CMS) measure (Cohen et al., 2000). We computed the industry scores of product patent effectiveness from the CMS and assigned each industry score to the product industry of patents in our survey (see Table 4).

However, one important question in this debate is: What is meant by "more effective" patents?One might think of several dimensions of "effectiveness" (or strength) of patents. Given a particular invention, and a particular set of claims, the first question is: How likely is something to get a patent? Many concerns raised in the debates about patent policy point to examples of low-level inventions that have received a patent, meaning that patents are protecting even small inventions (or possibly things that are not even inventions), and hence patents are strong, in the sense that they are protecting a wide range of inventions (Bessen and Meurer, 2008; Jaffe and Lerner, 2004).

A second dimension is how broadly those claims are interpreted.Patent claims describe the metes and bounds in technology space covered by the patent. The question is then: How close can a rival get to those claims as described without being accused of infringing?If those boundaries are wide (extending beyond the area directly claimed by the invention), then the patent can be seen as stronger or more effective.Comparing the US and Japan in the early 1990s, the US was seen as having more effective patents because the US had the doctrine of equivalents, while Japan did not (although Japan adopted this policy in 1998) (Cohen et al., 2002). Bessen and Meurer (2008)argue that unnecessarily broad interpretation of the boundaries around patents is one of the problems with the current system of overly strong patents (with uncertainty about the boundaries an additional problem).

Third, one could think of the extent to which anyone who encroaches on the boundary would be liable for infringement, and would be severely penalized (with large monetary judgments and strong injunctions) as a measure of how effective the patent is.Again, comparing the US and Japan, there was a strong sense in the 1980s and 1990s that the US courts were more likely to find for the patent owner, especially after the creation of the Court of Appeals of the Federal Circuit, and were likely to award higher judgments, and so the US had more effective patents (Cohen et al., 2002).

Thus, when thinking of a patent as a wall around an area of technology (the invention), one issue is how close to the core technology can a rival get without being accused of infringing (i.e. how large an area does the wall encircle), while a different issue is how likely it is that someone can successfully encroach on the covered technology space (i.e., how strong is the wall).

Prior work estimating the likelihood of licensing finds that patent effectiveness, as measured by the Carnegie Mellon survey measure, predicts the licensing payoff but not the patented invention's rate of licensing (Arora and Ceccagnoli, 2006).This suggests that the wall is stronger (the cost of gaining the licensing right is higher, because the potential penalties for entering without the license are higher), but not that the circle is bigger (because it does not increase the likelihood that rivals will need a license).These results help clarify the meaning of "effectiveness" in this measure. In our case, we argue that patents that are more effective, in the 
sense of increasing the expected penalty for using the patented technology (strength of the wall), but not increasing the likelihood that a particular use would be seen as infringing (circumference of the wall), should lead to more preemptive non-use.There are two reasons for this. The first is that, as patents are more effective in covering a given space (but do not necessarily cover more space), they will work better in preventing rivals from inventing around a focal commercialized invention (they will make better fences). Note that if more effective meant broader, then the single focal patent would be sufficient (so we would not see a relation between effectiveness and preemptive non-use). Similarly, if rivals' patents are more effective, they may be more dangerous in impinging freedom to operate, and hence increase the need to build up one's own patent portfolio of preemptive patents to use to both impinge on and hold off rivals in complex product technologies to ensure freedom to operate (Cohen et al., 2000). While strong patents may also encourage commercial use, we expect that the effect on preemptive non-use will dominate because in most industries patents are not the dominant form of appropriability and because other forms of appropriability may support commercialization and be less sensitive to patent effectiveness (Cohen et al., 2000; Fischer and Henkel, 2013).

\subsubsection{Competition}

The competitive conditions in a market may also affect the rates of preemptive versus commercial patents. Saunders (2001)argues that if preemptive patents are used for suppression, there should be less preemption in competitive markets, because rivals are more capable of introducing competing products (meaning that suppression is unlikely to succeed).However, if preemption is used to support a firm's commercialization of its own innovations, then we may observe more preemption as competition increases, because there is greater need to prevent inventing around or to ensure freedom to operate as the focal firm develops its technologies and commercialized innovations. In fact, Gilbert and Newbery (1982)argue that under competitive conditions with patent protection, firms have a higher incentive to conduct R\&D in response to potential rivals' $R \& D$, and therefore should generate more preemptive non-use patents. In early work, Gharrity (1966) observed no relation between competitive conditions and patent use rates, although he did not specifically break out non-use patents by types of non-use.

To test how competition affects rates of preemptive non-use(compared to commercial use), we measure competition in terms of firms competing for technological innovations (measured by industry average of the number of technology competitors, described in Table 4).

\subsubsection{Firm size}

Firm size is related to bargaining power in licensing negotiation, complementary assets, or better access to alliance partners, so large firms may have more commercial capability than small firms (Fosfuri, 2006; Gambardella et al., 2007; Gans and Stern, 2003). Furthermore, firms producing diverse products from a broad technology base (likely more associated with large firms) may be more likely to make a patent produced in one field profitable in another field (Nelson, 1959). However, large firms may also derive greater benefit from preemptive non-commercialized 
patents. Therefore, large firms may try to establish their proprietary position or secure time for developing the final product in the relevant product field by building broad patent portfolios, resulting in more preemptive patents (Blind et al., 2006; Bloom and Van Reenen, 2002). Similarly, Hall and Ziedonis (2001) argue that large firms develop preemptive patent portfolios to protect their investment in complementary assets. Motohashi (2008), using a measure that combines preemptive and failed patents, finds in Japan a curvilinear relationship between firm size and patent non-use (with medium-sized firms having the highest rates). European studies also show large firms are more likely to use patents for preventing potential entrants or for freedom-to-operate exchanges (e.g., cross-licensing) (Blind et al., 2009; de Rassenfosse, 2012; Giuri et al., 2007). Gharrity (1966)shows patent use rates are higher in unlisted firms than in listed firms, suggesting patent non-use, including preemptive non-use, may be greater in larger firms.Recent data by De Rassenfosse (2012) also shows large firms have higher rates of non-use.

These studies suggest large firms may have the advantage in commercializing patents and also in using patents for preemption, leave the net effect unclear. Hence we empirically test the relationship between firm size and the probability of preemptive non-use over commercial use of patents. For the firm size variable, we create, from our survey, a dummy variable, which is 1 for large firms (i.e. employees $>500$ ), and 0 for SMEs (cf. de Rassenfosse, 2012).

\subsubsection{Fragmentation of patent rights}

Firms may need outside, complementary inventionsto commercialize their technologies.Ziedonis (2004) argues that if the outside patents the firm needs are owned by one or a few entities, the firm can access complementary technologies through ex ante contractual solution such as joint ventures or patent pools. On the other hand, if outside patents are assigned to many different owners, thereby making ex ante mechanisms costly, the firm has more incentive to build large patent portfolios to increase their ex post bargaining power (Ziedonis, 2004). She shows, among semiconductor firms, that dispersion of patent rights over outside inventions increases the firm's incentive to patent. Noel and Schankerman (2013)also find in computer software that greater fragmentation of patent rights by rivals encourages the firm to invest in R\&D and patent more. These prior studies predict the effects of fragmented patent rights on the focal firm's patenting in general. However, we further test the effect on the different uses of patents (i.e., whether fragmentation of patent rights drives more preemptive non-use than commercial use of patents, as predicted).Furthermore, we expand on prior work by not limiting to one industry or to public firms.

Based on Ziedonis (2004), we constructed a modified fragmentation index, which measures the extent to which the prior art is owned by multiple alters. The fragmentation index of patent $k$ assigned to firm $i_{k}$ is calculated as

FRAG $_{\mathrm{k}}=1-\sum_{j_{k} \neq i_{k}}\left(\frac{\text { NBCITES }_{j_{k}}}{\text { NBCITES }_{k}-\text { NBCITES }_{i_{k}}}\right)^{2}$,

where $j_{k}$ refers to each unique assignee on the set of patents cited by a patent $k$. NBCITES $S_{k}$ is the 
number of the US patents cited by patent $\mathrm{k}, N B C I T E S_{i_{k}}$ the number of self-cited US patents, and $N B C I T E S_{j_{k}}$ the number of the US patents cited by patent $k$ and assigned to $j_{k}$. We consider cited patents filed since 1984, because most earlier patents would have expired by the time the focal patents were granted and, therefore, would not impinge on exploiting the focal patent. If all patents cited by firm $i$ belong to one assignee firm, the index is zero whereas as assignee firms of those cited patents are more widely dispersed, the index approaches one.

Table 4 gives the details of the measures of these four main variables.

\section{--INSERT TABLE 4 ABOUT HERE-}

\subsubsection{Control Variables}

In our tests, we also control for thetechnical value of the invention (measured by the inventor's ranking of the technical significance of the patent compared to other patents in its field in the same year, on a 4-point scale [Top 10\%; Top 25\%, but not top 10\%; Top half, but not top 25\%; bottom half]).We expect patents with higher technical value to have higher rates of commercialization. We also control forpatent breadth (measured by the count of IPCs) as another measure of value (Lerner, 1994). We also control for product (v. process) invention, measured by a question in our survey, as process patents may have higher rates of preemptive non-use(Cohen, et al., 2000). We also include dummies for assignee countries (US and Japan with Europe as the reference group), since countries may vary in their tendency to engage in preemptive non-use of patents(Cohen et al., 2002; de Rassenfosse, 2012). Finally, we control for filed year, as older cohorts of patents have had more time to be commercialized.

For dependent variables, our primary comparison is preemptive patents (any preemptive non-use, non-exclusive of prospective or failed patents) vs. commercial patents (union of inhouse, licensing or use for a startup). However, we further compare preemptive patents vs. any in-house use of patents and preemptive patents vs. any licensed patents. Table 5displays the descriptive statistics and correlation matrix.

\section{--INSERT TABLE 5ABOUT HERE-}

\subsection{Results}

We first use probit regressions to test the effects of potential drivers of preemptive patents (v. commercial patents). First, patent effectiveness is presumed to positively affect both commercial use and preemptive non-use of patents, but with arguments suggesting that preemptive nonusemay be especially sensitive to patent strength. Column 1 in Table 6indicates that the impact of patent strength is indeed larger on preemptive non-use compared to commercial use. This result is consistent for each type of commercial use (any in-house use and any licensed 
patents). ${ }^{12}$

Second, we find greater technology competition increases the rate of preemptive patents(compared to commercialized patents), although the effect is not there when we limit the comparison set to licensed patents. This suggests that preemptive patents are especially critical to support the appropriability of products that the firm itself commercializes.

Third, Table 6shows that firm size consistently has significant positive effects across all models, as expected (Columns 1 to 3 ). ${ }^{13} \mathrm{We}$ also tested a model substituting industry dummies for the industry-level measures of patent effectiveness and competition, and the effects of firm size are robust (results available from author). Finally, we do not find any strong effect on preemptive patents versus commercialized patents from fragmentation of patent rights, unlike prior work measuring rates of patenting (Noel and Schankerman, 2013; Ziedonis, 2004).

We further estimate a multinomial probit model to examine the effects of those determinants on preemptive non-use considering other non-use categories as well as commercial use. Here, in order to make the categories exclusive (see Fig. 2), we define the categories as commercial use, (any) preemptive non-use, (pure) failed patents, and prospective patents (as other, meaning neither any preemptive nor pure failed). The results, in columns 4 to 6 of Table 6 , first, show that increasing patent effectiveness raises the probability of preemptive non-use relative to that of commercial use. Both competition and firm size increase the probability of any non-use (preemptive, prospective, failed) relative to that of commercial use. To give a sense of the magnitude of these effects, Table 7 shows changes in the predicted probabilities given changes in explanatory variables. For example, a change in patent effectiveness from minimum to maximum raises the probability of preemptive non-use by about 12 percentage points and decreases the probability of commercial use by 8 percentage points.

Among our control variables, as expected, higher technical significance is always associated with more commercial use rather than preemptive non-use. Similarly, higher technical significance is also associated with lower rates of failed patents. This suggests that, among a suite of related patents (for example alternative technologies applicable to a product market), the highest value patent would be commercialized and the preemptive patents would be the "also ran" solutions, with the preemptive non-use patents supporting the appropriability of the high-value patent. We also find that patents assigned to Japanese firms are more likely to be preemptive non-use patents, compared to commercialized (or in-house use) patents (cf. Cohen et al., 2002).

\footnotetext{
${ }^{12} \mathrm{We}$ use the USPTO US patent class-product industry NAICS concordance to assign patents to the relevant product industry. Therefore, our industry variables (patent effectiveness and competition) are also controlling for technology classes. When we regress patent effectiveness and competition, respectively, on 34 technology class dummies, the R-squared for patent effectiveness is .40 and for competition is .47 .

${ }^{13}$ Although we did not have any specific expectations for the rates of preemptive non-use versus startup use, we also ran this model. The results are largely similar to preemptive versus licensing (with patent effectiveness, size and value all significant, in the same directions as in Column 3). Results are available from author.
} 
--INSERT TABLE 6ABOUT HERE-

--INSERT TABLE 7 ABOUT HERE-

\section{Discussion and Conclusions}

Our results show almost half of triadically patented inventions are not used, and that there are different types of non-use of patents. Some non-commercialized patents may still be prospects for future commercialization, and others may be failed patents. Moreover, some patents play an important role in firm strategy beyond protecting commercialized inventions or facilitating licensing. The preemptive non-use of patents includes providing insurance against infringement suits, ensuring freedom to operate, and preventing rivals from inventing around a commercialized invention. For the US, we find $45 \%$ of triadic patents are not commercially used. This iscomparable to Torrisi et al. (2015)'s statistics, where 39\% of patent applications from the US respondentsare not used. Out of non-commercialized patents (i.e. non-use patents), about $40 \%$ are (non-exclusively) preemptive patents ( $17 \%$ of all triadic patents), but only $6 \%$ end up as exclusively preemptive patents (i.e., only about $3 \%$ of all triadic patents). We also find significant heterogeneity in rates of preemptive non-use. Stronger patent protection, more technological competition and large firm size predict relatively more preemptive patents rather than commercial patents, while technical value shows the opposite result.

While many prior studies measure strategic patenting using questions regarding motivations for patenting (sometimes combined with measures of patent commercialization)(Cohen et al., 2000; Giuri et al., 2007; Blind et al., 2009; Torrisi et al., 2015), in this paper we focus on the outcome of the patent (use or non-use) and the reasons for non-use of a particular patent. Our approach is novel in asking for the different reasons for non-use of patents, rather than relying on the motives for patenting those non-used patents.Furthermore, as we show in Table 1, reported motives for patenting are not very predictive of the final disposition of patents. In addition, from a policy perspective, it is largely the uses/non-uses of the patents, and the reasons for non-use, that arecritical, whatever the original intent. Finally, our analysis allows us to see how the fate of patents (whatever their initial intent) is affected by firm and market characteristics..

\subsection{Limitations}

There are some important limitations to this study. First, uses of patents are identified based on querying one of the inventors. Although the survey is directed to the lead inventor, who is likely to be well-informed on the invention process, some may not know about the commercialization process of their invention. This may be especially true in large firms. We find the likelihood of reporting "don't know" on the uses of the invention increases with firm size.This gives us both concern and some comfort.The concern is that as firm size increases, the errors in reporting the uses of the patent may also increase. However, there is some comfort in the fact that inventors felt free to use "don't know" and that as the expected likelihood of not knowing increases, the 
likelihood of invoking that option also increases, so that the completed cases may be taken as the ones where the respondent felt confident enough to answer the question. Future surveys might check the feasibility of asking different members of the organization for information about the generation versus the uses of an invention (as in the US Business R\&D and Innovation Survey by NSF).

Second, the sample is composed of triadic patents. The additional costs incurred by filing patents in multiple jurisdictions affect the sample characteristics in two different ways. First, because SMEs may have greater financial constraints, they may have been underrepresented in this sampling frame compared to a sample of strictly US patents, although comparisons with population data suggests this bias is modest (Jung, 2009). Also, the additional costs may have the effect of raising the threshold of patenting to sieve out low-quality patents, which might be even more likely to be non-use patents.However, the finding that failed patents are more common than preemptive patents, even among triadic patents, suggests that preemptive patents may not dominate even in a broader sample.Prior work cited by Gharrity (1966) suggests similar conclusions.

\subsection{Implications}

Our results have important implications for debates on patent policy. First, we find that the higher the technological quality of patents, the more likely they will be commercialized (rather than used for preemption). The Smith-Leahy America Invents Act (2011) aims to raise patent quality by enhancing the examination process, expanding the ability of the public to submit prior art during the examination process, and implementing new review processes. All of these are ways to increase the patenting threshold and therebyshould reduce the rate of non-use patents. Still, we find that even triadic patents, which have already met a high threshold, are often preemptive non-use patents. The America Invents Act (AIA) has other provisions that might affect preemptive non-use of patents. The expanded prior-use rights provisions might reduce the need for patent races that generate preemptive patents (related to freedom to operate). On the other hand, a shift toward first-inventor-to-file might encourage generating preemptive patents, especially during the early stages of a technology trajectory when there is great need to cover options quickly, before a rival patents and blocks that channel (cf., Cohen, et al., 2002).

Following the AIA, there have been further calls to rein in non-practicing entities (sometimes called "trolls") (Bessen and Meurer, 2008). These non-practicing entities also undermine the preemptive non-use of patents by producers to ensure freedom to operate, because the so-called troll is not deterred by a large patent portfolio, since the troll produces nothing that can infringe on those preemptive patents.However, many non-use patents have the purpose of supporting a commercialized invention by preventing rivals from inventing around or by ensuring the focal firm the freedom to operate. Since preemptive patents are, by definition, not practiced, the definition of non-practicing entity in these policy reforms should not be so broad as to include these preemptive non-use patents. Our results suggest the need for caution in patent reforms so as to not undermine legitimate preemptive non-use of patents. Preemptive non-use of 
patents may be critical in supporting appropriability for commercialized inventions, and hence may be an important part of the incentives for R\&D and innovation.

We also show that preemptive non-use, relative to commercial use, is higher in industries where patent protection is more effective. We have seen a significant increase in patent strength in the US and elsewhere over the last three decades, raising concerns of adverse consequences (Jaffe and Lerner, 2004; Mazzoleni and Nelson, 1998). Although recent Supreme Court decisions (such as Bilski v. Kappos (2010) [limiting method patents], eBay v. MercExchange (2006) [removing a presumption of injunctive relief], Association for Molecular Pathology v. Myriad Genetics (2013) [limiting gene patents], etc.) seem to have limited patent strength, one concern is that stronger patents may encourage more preemptive non-use of patents, creating thickets of non-commercialized but potentially dangerous patents, raising barriers to innovation (Heller and Eisenberg, 1998; Shapiro, 2001). Our finding that stronger patents are associated with a greater ratio of preemptive patents to commercial patents suggests that reforms designed to strengthen patents may have encouraged firms to patent more of their inventions and to stockpile patents in case they are needed (Hall and Ziedonis, 2001).

However, out of non-use patents, the share of preemptive patents is still much smallerthan that of failed patents. Rather than focusing on preventing preemptive patents, a more important problem may be how to decrease failed patents. Perhaps more developed capital markets, or market mediators for patents, could increase the ability to commercialize some kinds of failed patents (Kukkonen, 1998). Since rates of failed patents are higher in fast moving industries (Table 3), some share of failed patents may simply be a cost firms have to pay for operating in fast-moving industries.

Arguments about patent non-use are often couched in terms of abuse of the patent right and suppression of technological progress (Bessen and Meurer, 2008; Saunders, 2001). However, preemptive patents may beneeded to get market exclusivity, since rival versions of similar technologies creates market competition, rent dissipation and loss of incentives. Hence, a wellfunctioning patent system requires non-use patents that support other patents. Such preemptive non-use can become abuse when preemption becomes anti-trust (conspiring to keep others out) (Saunders, 2001). And, even though preemptive non-use can delay follow-on innovation, this is no different than the delay in follow-on innovation that the primary patent itself gives. Put differently, the delay in rivals' use of technology from the preemptive patent is what is necessary to fulfill the exclusivity function granted in the commercialized patent. Consistent with this, we find that greater competition is associated with greater rates of preemptive patents. This suggests that preemptive patents are especially critical to support the appropriability of products that the firm itself commercializes.

The key contribution of our findings to policy debates is in highlighting that patent non-use is not rare, and that this non-use includes preemptive non-use, which is, by definition, related to protecting the firms' commercialized products or processes. Hence, arguments about the need to put limits on non-practicing entities need to take account of the importance of "non-practiced" patents for firms' commercialization of innovations. Furthermore, making patents more effective 
seems to increase (rather than decrease) reliance on preemptive non-use of patents. In addition, such preemptive non-use is most common when technology competition is greater. Hence, patent reforms must be sensitive to the legitimate function preemptive patents play in an innovation system, especially one characterized by rapid technological change, significant technical competition, and effective patents.

Given these findings, we need to see if, on balance, the private innovation incentives generated by these patents are worth the cost to the public of granting these exclusive rights. This is an important area for future work, although, as Thomas Jefferson pointed out, also a very difficult question to answer. 


\section{References}

Allison, J.R., Lemley, M.A., Walker, J.H., 2009. Extreme value or trolls on top? . University of Pennsylvania Law Review 158.

Anand, B.N., Khanna, T., 2000. The structure of licensing contracts. The journal of industrial economics 48, 103-135.

Anton, J.J., Yao, D.A., 2004. Little patents and big secrets. RAND Journal of Economics, 1-22.

Arora, A., Ceccagnoli, M., 2006. Patent protection, complementary assets, and firms' incentives for technology licensing. Management science 52, 293-308.

Arora, A., Gambardella, A., 2010. Ideas for rent. Industrial and Corporate Change 19, 775-803.

Arundel, A., 2001. The relative effectiveness of patents and secrecy for appropriation. Research policy 30 , 611-624.

Baba, Y., Walsh, J.P., 2010. Embeddedness, social epistemology and breakthrough innovation: The case of the development of statins. Research policy 39, 511-522.

Baumol, W.J., 2002. The free-market innovation machine. Princeton university press.

Bessen, J., Meurer, M.J., 2008. Patent Failure. Princeton University Press, Princeton, NJ.

Blind, K., Cremers, K., Mueller, E., 2009. The influence of strategic patenting on companies' patent portfolios. Research policy 38, 428-436.

Blind, K., Edler, J., Frietcsh, R., Schmoch, U., 2006. Motives to patent. Research policy 35, 655-672.

Bloom, N., Van Reenen, J., 2002. Patents, real options and firm performance. The Economic Journal 112, C97-C116.

Cohen, W.M., Goto, A., Nagata, A., Nelson, R.R., Walsh, J.P., 2002. R\&D spillovers, patents and the incentives to innovate in Japan and the United States. Research policy 31, 1349-1367.

Cohen, W.M., Nelson, R.R., Walsh, J.P., 2000. Protecting their intellectual assets: Appropriability conditions and why US manufacturing firms patent (or not), NBER Working Paper \#7552.

Czarnitzki, D., Toole, A.A., 2011. Patent protection, market uncertainty, and R\&D investment. The Review of Economics and Statistics 93, 147-159.

de Rassenfosse, G., 2012. How SMEs exploit their intellectual property assets. Small Business Economics 39, 437-452.

de Rassenfosse, G., Guellec, D., 2009. Quality versus quantity, 4th annual conference of the EPIP association.

Dillman, D.A., 2007. Mail and internet surveys. John Wiley \& Sons, New York.

Fischer, T., Henkel, J., 2013. Complements and substitutes in profiting from innovation-A choice experimental approach. Research policy 42, 326-339.

Fosfuri, A., 2006. The licensing dilemma. Strategic Management Journal 27, 1141-1158.

Gambardella, A., Giuri, P., Luzzi, A., 2007. The market for patents in Europe. Research policy 36, 11631183.

Gans, J.S., Hsu, D.H., Stern, S., 2008. The impact of uncertain intellectual property rights on the market for ideas. Management science 54, 982-997.

Gans, J.S., Stern, S., 2003. The product market and the market for "ideas". Research policy 32, 333-350.

Gharrity, N.J., 1966. The use and non-use of patented inventions, Economics. The Johns Hopkins University, Baltimore, MD.

Gilbert, R.J., Newbery, D.M., 1982. Preemptive patenting and the persistence of monopoly. The American Economic Review, 514-526.

Giuri, P., Mariani, M., Brusoni, S., Crespi, G., Francoz, D., Gambardella, A., Garcia-Fontes, W., Geuna, A., Gonzales, R., Harhoff, D., 2007. Inventors and invention processes in Europe. Research policy 36, 1107-1127.

Grindley, P.C., Teece, D.J., 1997. Managing intellectual capital. California Management Review 39, 8-41. Hall, B.H., Helmers, C., Rogers, M., Sena, V., 2012. The choice between formal and informal intellectual property. National Bureau of Economic Research.

Hall, B.H., Ziedonis, R.H., 2001. The patent paradox revisited. RAND Journal of Economics, 101-128. 
Heller, M.A., Eisenberg, R.S., 1998. Can patents deter innovation? Science 280, 698-701. Hounshell, D.A., Smith, J.K., 1988. Science and corporate strategy. Cambridge University Press. Jaffe, A., Lerner, J., 2004. Innovation and its discontents. Princeton University Press, Princeton, NJ. Jaffe, A.B., 2000. The US patent system in transition. Research policy 29, 531-557. Jefferson, T., 1813. Thomas Jefferson to Isaac McPherson, 13 Aug. 1813, The Founders' Constitution Volume 3 Article 1, Section 8, Clause 8, Document 12, http://presspubs.uchicago.edu/founders/documents/a1 8 8s 12.html The University of Chicago Press. Retrieved May 27, 2015.

Jung, T., 2009. Uses and nonuses of patented inventions, School of Public Policy. Georgia Institute of Technology, Atlanta, GA.

Kortum, S., Lerner, J., 1999. What is behind the recent surge in patenting? Research policy 28, 1-22. Kukkonen, C.A., 1998. The use of patent licensing center as an intermediary for facilitating the licensing of commercially viable, unused patents. Virginia Journal of Law and Technology 3.

Lemley, M.A., Shapiro, C., 2005. Probabilistic patents. Journal of Economic Perspectives, 75-98. Lerner, J., 1994. The importance of patent scope. The RAND Journal of Economics, 319-333. Levin, R.C., Klevorick, A.K., Nelson, R.R., Winter, S.G., Gilbert, R., Griliches, Z., 1987. Appropriating the returns from industrial research and development. Brookings papers on economic activity, 783-831. Macdonald, S., 2004. When means become ends. Information Economics and Policy 16, 135-158. Mazzoleni, R., Nelson, R.R., 1998. The benefits and costs of strong patent protection: a contribution to the current debate. Research policy 27, 273-284.

Merges, R., 1994. Intellectual property rights and bargaining breakdown. Tenn. L. Rev. 62, 75.

Motohashi, K., 2008. Licensing or not licensing? Research policy 37, 1548-1555.

Nelson, R.R., 1959. Simple economics of basic scientific research. The Journal of Political Economy 67, 297-306.

Noble, D.F., 1977. America by design. Alfred A Knopf, New York.

Noel, M., Schankerman, M.A., 2013. Strategic patenting and software innovation. The journal of industrial economics 61, 481-520.

Plamondon, S., 2015. Congress is reconsidering “anti troll” legislation, Intellectual Property Law Blog. Rivette, K.G., Kline, D., 2000. Rembrandts in the attic. Harvard Business School Press, Boston, MA.

Saunders, K.M., 2001. Patent nonuse and the role of public interest as a deterrent to technology suppression. Harv. JL Tech 15, 389.

Shapiro, C., 2001. Navigating the patent thicket, Innovation Policy and the Economy, Volume 1. MIT press, pp. 119-150.

Sheehan, J., Martinez, C., Guellec, D., 2004. Understanding business patenting and licensing. OECD Publishing.

Turner, J.S., 1998. The nonmanufacturing patent owner. California Law Review, 179-210.

van Zeebroeck, N., Stevnsborg, N., De La Potterie, B.V.P., Guellec, D., Archontopoulos, E., 2008. Patent inflation in Europe. World Patent Information 30, 43-52.

Walsh, J.P., Lee, Y.-N., Nagaoka, S., 2015. Openness and innovation in the US: Collaboration form, idea generation and implementation, Working paper.

Walsh, J.P., Nagaoka, S., 2009. How'open'is innovation in the US and Japan? Evidence from the RIETIGeorgia Tech inventor survey. RIETI Discussion Paper Series 09-E-022.

Ziedonis, R.H., 2004. Don't fence me in. Management science 50, 804-820. 
Table 1. Motive to patent and patent use.

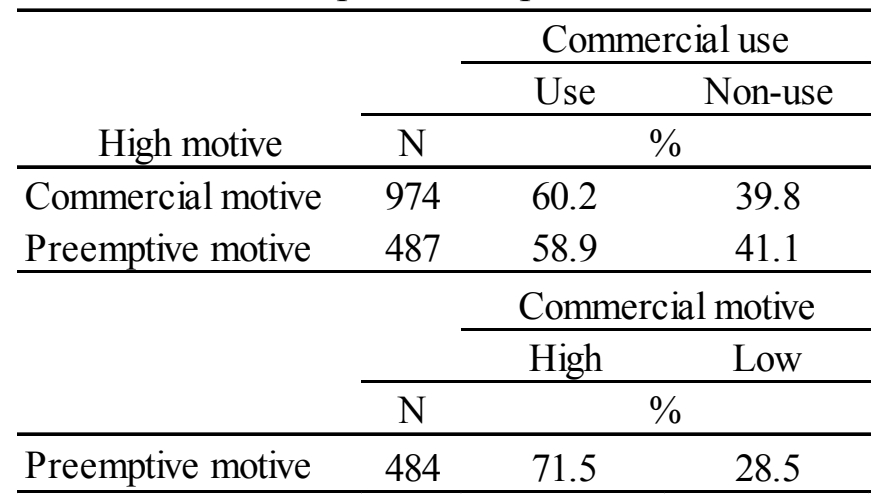


Figure 1. Reasons for non-use of patents (percent "yes", among non-use patents).

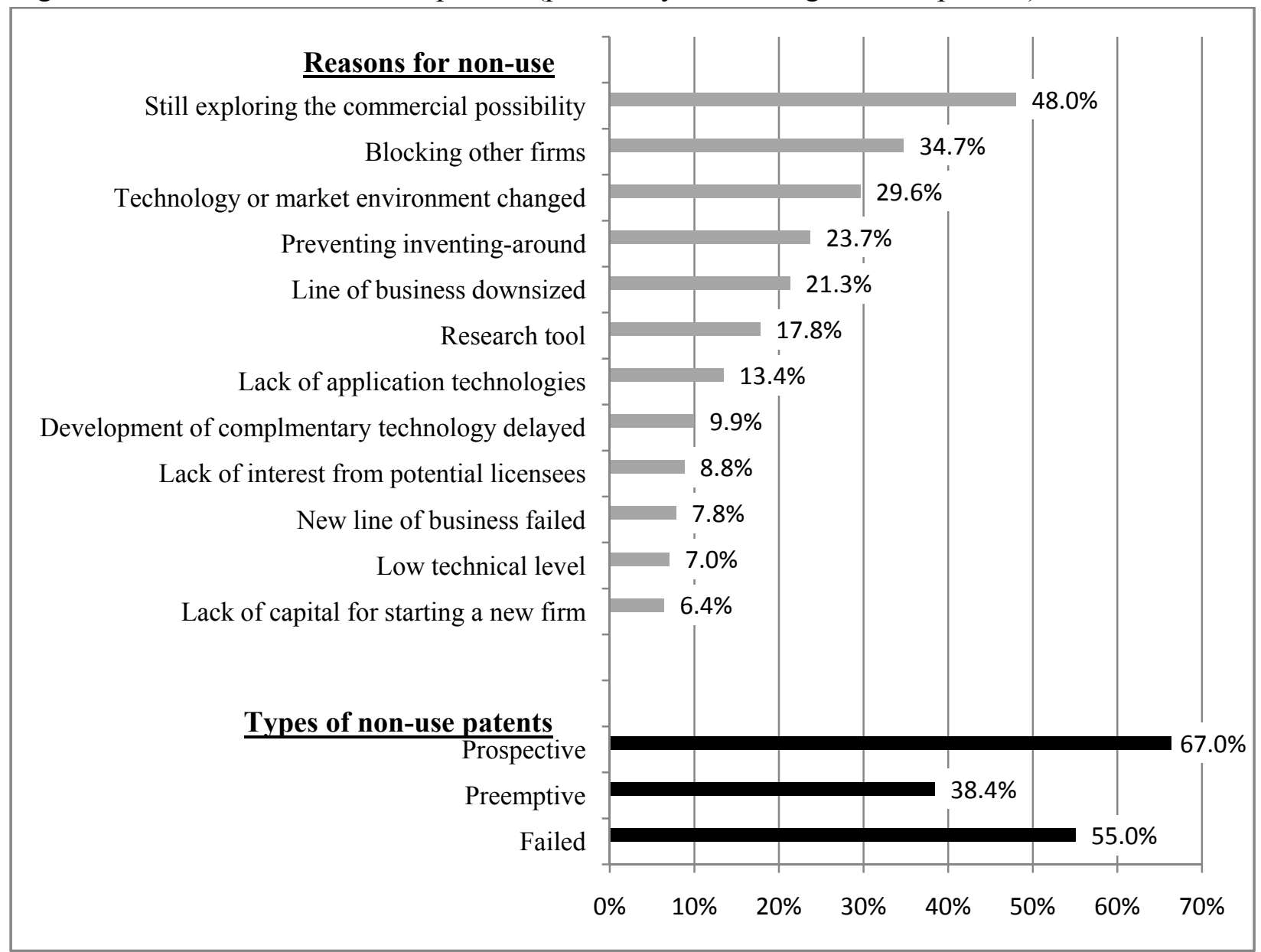

Note: Out of non-commercialized patents $(\mathrm{N}=625)$. 
Table 2. Types of non-use patents.

\begin{tabular}{|c|l|}
\hline Types of non-use patents & \multicolumn{1}{c|}{ Reasons for non-use } \\
\hline Prospective & $\begin{array}{l}\text { Still exploring the commercial possibility } \\
\text { Research tool (to develop other commercial technologies) } \\
\text { Lack of application technologies for this basic invention } \\
\text { Development of complementary technology delayed }\end{array}$ \\
\hline Preemptive & $\begin{array}{l}\text { Blocking other firms } \\
\text { Preventing inventing-around }\end{array}$ \\
\hline \multirow{2}{*}{ Failed } & $\begin{array}{l}\text { Technology or market environment changed (reducing the } \\
\text { value of this invention) } \\
\text { Low technical level } \\
\text { Lack of interest from potential licensees } \\
\text { Lack of capital for starting a new firm on the technology } \\
\text { Line of business downsized } \\
\text { New line of business failed }\end{array}$ \\
\hline
\end{tabular}


Figure 2. Venn diagram of patent non-use types.

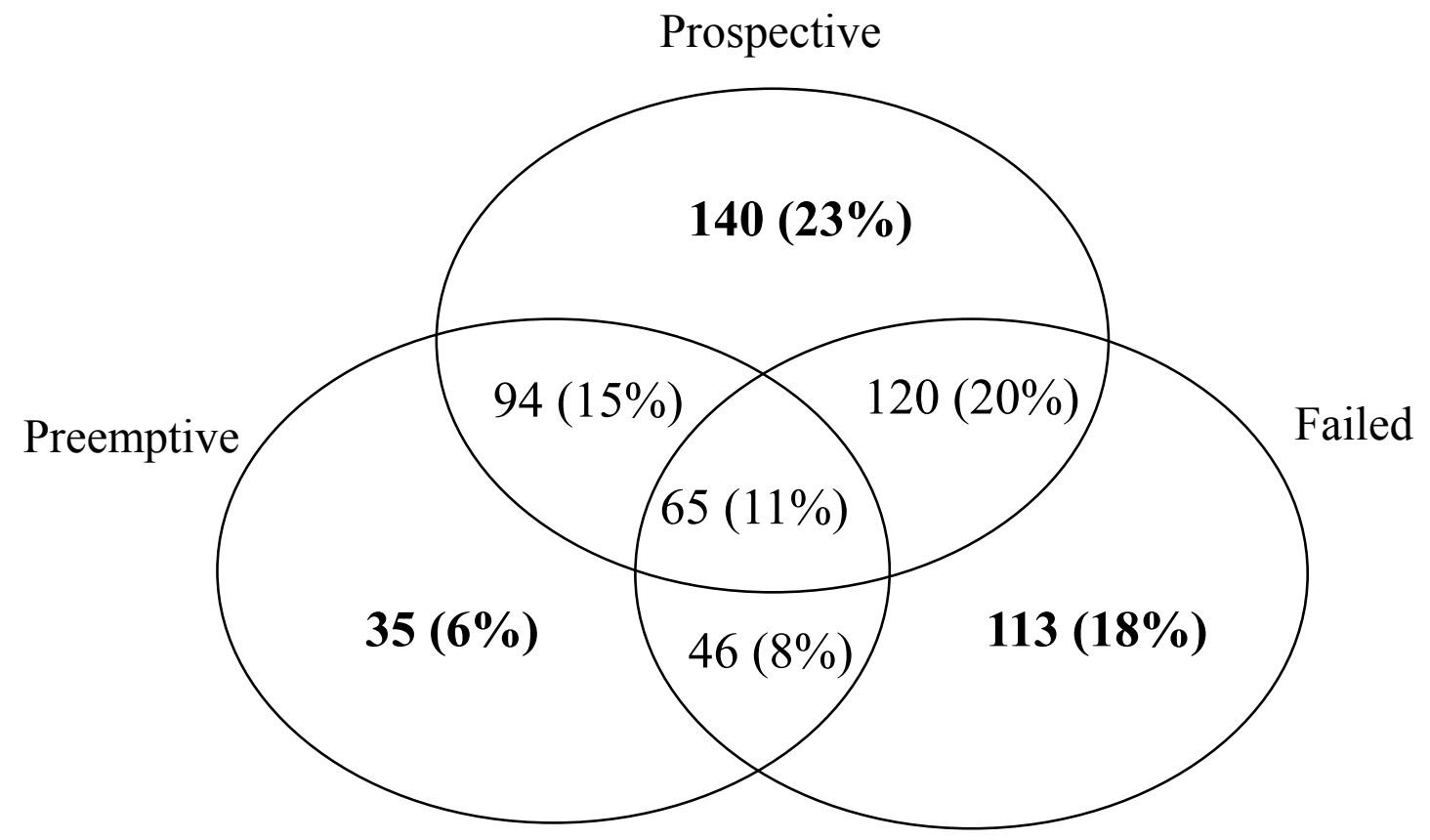

Note: $\mathrm{N}=613(100 \%) ; 12$ cases not defined as any of the three types excluded. 
Table 3. Share of three types of non-use patents by industry and firm characteristics.

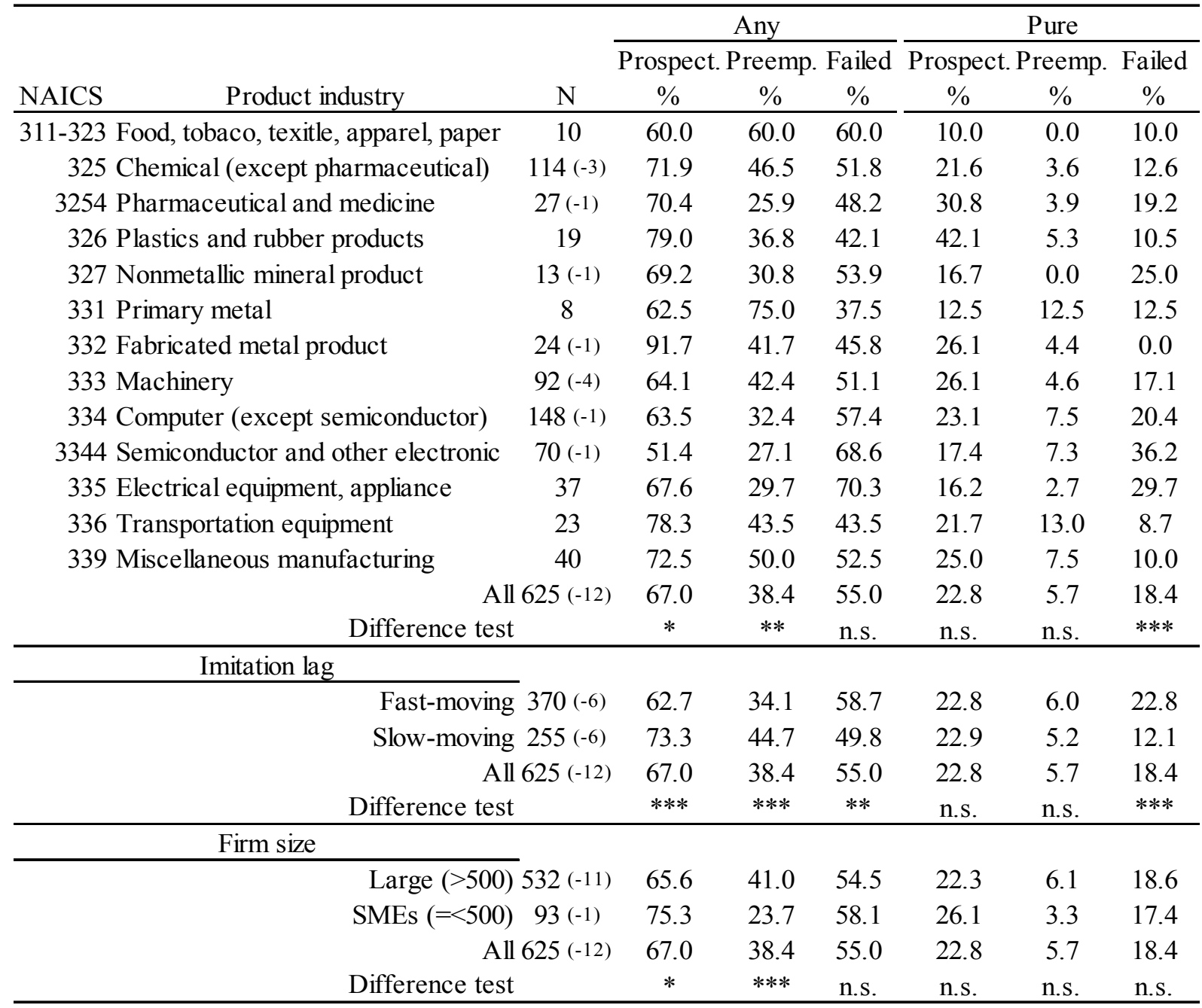

$* * * \mathrm{p}<.01,{ }^{* *} \mathrm{p}<.05,{ }^{*} \mathrm{p}<.10$, n.s. $=$ not significant

Other cases (= total 12) displayed in ( ) excluded for statistics of three types of "pure" non-use, consistent with Figure 2.

Imitation lag: Industry average of speed at which rivals introduced competing product innovations, dichotomized (from CMS) 
Table 4. Main variable construction

\begin{tabular}{|c|c|c|}
\hline Variable & Measure & Source \\
\hline $\begin{array}{l}\text { Patent } \\
\text { effectiveness }\end{array}$ & $\begin{array}{l}\text { The industry average of mid-point percentage in product } \\
\text { patent effectiveness from the question "during the last three } \\
\text { years, for what percent of your product innovations were } \\
\text { each of the following (e.g., secrecy, patent protection, etc.) } \\
\text { effective in protecting your firm's competitive advantage } \\
\text { from those innovations?" with categories of below } 10 \%, 10 \text { - } \\
40 \%, 61-90 \% \text {, and over } 90 \% \text {. }\end{array}$ & CMS \\
\hline Competition & $\begin{array}{l}\text { The industry average of the mid-point number of technology } \\
\text { competitors from the question "[in North America] how } \\
\text { many firms are able to introduce competing innovations in } \\
\text { times to effectively diminish your firm's profit from your } \\
\text { innovation?" with categories of } 0,1-2,3-5,6-10,11-20 \text {, and } \\
>20 \text {. }\end{array}$ & CMS \\
\hline Firm size & Large firm $=1$ if employees $>500$, otherwise 0 & $\begin{array}{l}\text { Inventor } \\
\text { Survey }\end{array}$ \\
\hline $\begin{array}{l}\text { Fragmentation } \\
\text { index }\end{array}$ & $\begin{array}{l}\text { The fragmentation index of patent } k \text { assigned to firm } i_{k} \text { is } \\
\text { calculated as } \\
\text { FRAG }_{\mathrm{k}}=1-\sum_{j_{k} \neq i_{k}}\left(\frac{N B C I T E S_{j_{k}}}{N B C I T E S_{k}-N B C I T E S_{i_{k}}}\right)^{2} \\
\text { where } j_{k} \text { refers to each unique assignee on the set of patents } \\
\text { cited by a patent } k . N B C I T E S_{k} \text { is the number of the US } \\
\text { patents cited by patent } \mathrm{k}, N B C I T E S_{i_{k}} \text { the number of self- } \\
\text { cited US patents, and } N B C I T E S_{j_{k}} \text { the number of the US } \\
\text { patents cited by patent } k \text { and assigned to } j_{k} \text {. }\end{array}$ & Bibliometric \\
\hline
\end{tabular}


Table 5. Descriptive statistics and correlation matrix.

\begin{tabular}{|c|c|c|c|c|c|c|c|c|c|c|c|c|c|c|}
\hline \multirow{2}{*}{ Variable } & \multirow{2}{*}{$\mathrm{N}$} & \multirow{2}{*}{ Mean } & \multirow{2}{*}{$\mathrm{SD}$} & \multirow{2}{*}{ Min } & \multirow{2}{*}{ Max } & \multicolumn{9}{|c|}{ Correlation } \\
\hline & & & & & & 1 & 2 & 3 & 4 & 5 & 6 & 7 & 8 & 9 \\
\hline 1 Preemptive (v. commercial) & 1137 & 0.21 & 0.41 & 0 & 1 & 1.00 & & & & & & & & \\
\hline 2 Preemptive (v. in-house use) & 1050 & 0.23 & 0.42 & 0 & 1 & 1.00 & 1.00 & & & & & & & \\
\hline 3 Preemptive (v. licensed) & 404 & 0.59 & 0.49 & 0 & 1 & 1.00 & 1.00 & 1.00 & & & & & & \\
\hline 4 Patent effectiveness & 1618 & 35.27 & 7.84 & 17.83 & 53.31 & 0.03 & 0.02 & 0.03 & 1.00 & & & & & \\
\hline 5 Competition & 1618 & 3.70 & 0.70 & 2.52 & 5.83 & 0.04 & 0.06 & -0.08 & -0.09 & 1.00 & & & & \\
\hline 6 Large firm & 1618 & 0.79 & 0.41 & 0 & 1 & 0.16 & 0.16 & 0.33 & -0.09 & -0.03 & 1.00 & & & \\
\hline 7 Fragmentation index & 1616 & 0.68 & 0.28 & 0 & 0.98 & -0.04 & -0.05 & -0.03 & -0.02 & -0.14 & -0.07 & 1.00 & & \\
\hline 8 Technical value & 1336 & 2.21 & 1.06 & 1 & 4 & -0.21 & -0.22 & -0.31 & 0.03 & 0.01 & -0.16 & 0.05 & 1.00 & \\
\hline 9 Product invention & 1534 & 0.79 & 0.41 & 0 & 1 & -0.03 & -0.04 & 0.00 & 0.06 & -0.03 & -0.04 & 0.03 & 0.06 & 1.00 \\
\hline 10 Patent breadth & 1618 & 4.73 & 3.31 & 0 & 28 & 0.06 & 0.06 & 0.06 & 0.11 & 0.16 & -0.02 & -0.03 & $\mathbf{0 . 0 7}$ & 0.00 \\
\hline
\end{tabular}

Bold: $\mathrm{p}<.05$ 
Table 6. Estimates of determinants of preemptive patents

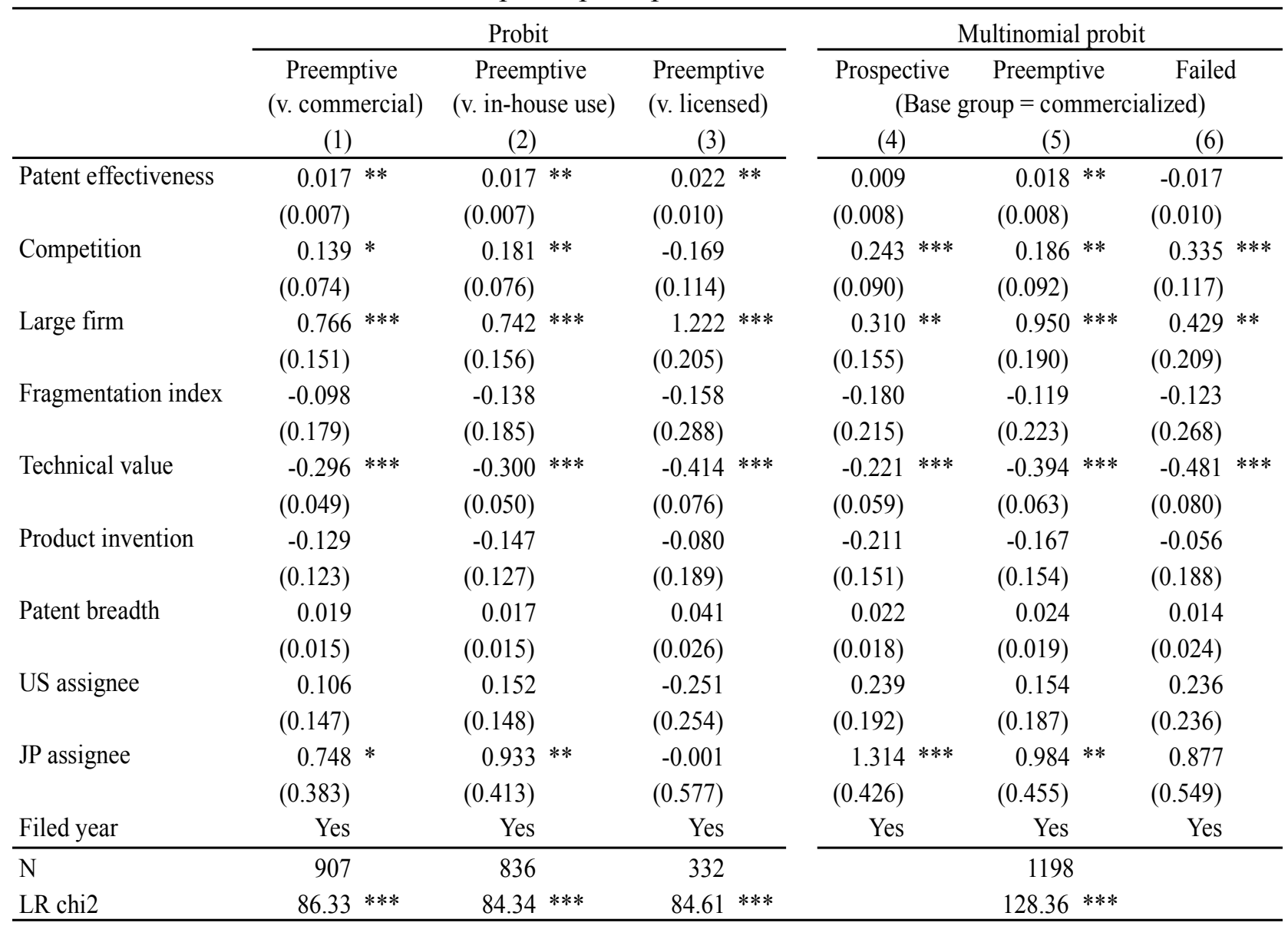

$* * * \mathrm{p}<.01, * * \mathrm{p}<.05, * \mathrm{p}<.10$

Note: Preemptive $=$ any preemptive

Failed $=$ pure failed

Prospective $=$ the rest (including those overlapped with failed patents, but not preemptive patents. See Figure 2)

Patent effectiveness: industry average of share of product innovations for which patents were effective in "protecting your firm's competitive advantage from those innovations" (from CMS)

Competition: industry average of number of technology competitors (from CMS)

Large firm: greater than 500 employees

Fragmentation index: dispersion in ownership of cited prior art patents (see Table 4)

Technical value: self-reported rank of technical significance of patented invention compared to other inventions in the same field in the same year (from Inventor survey) 
Table 7. Changes in the predicted probabilities.

Commercial Prospective Preemptive Failed

(1)

(2)

(3)

(4)

$\underline{\text { Patent effectiveness }}$

$\min \rightarrow \max$

$\begin{array}{llll}-0.081 & 0.046 & 0.117 & -0.082\end{array}$

25 th $\rightarrow 75$ th

$\begin{array}{llll}-0.032 & 0.017 & 0.044 & -0.030\end{array}$

$-+\mathrm{SD} / 2$

$-0.018$

0.010

$0.025 \quad-0.018$

Competition

$\min \rightarrow \max$

$-0.245$

0.107

0.048

0.091

25 th $\rightarrow 75$ th

$\begin{array}{llll}-0.065 & 0.029 & 0.014 & 0.022\end{array}$

$-+\mathrm{SD} / 2$

$-0.050$

0.022

$\begin{array}{ll}0.011 & 0.017\end{array}$

Firm size

SME $\rightarrow$ Large firm

$-0.158$

0.016

0.124

0.018 
Appendix A. Question wording of reasons for patent non-use.

If this patent was not used either as a commercial product/process/service by the applicant firm, for licensing, or for starting a new company, what are the reasons for it not yet being commercialized? Please check all that apply.

a. We are still actively exploring the commercial possibilities of this invention

b. The technology is used internally as a research tool to develop other commercial technologies

c. The patent is used or was used for blocking other firms from patenting similar inventions

$\mathrm{d}$. The patent is used or was used for preventing inventing-around our products/processes by other firms

e. The technology or market environment has changed so that it reduced the value of this invention

f. The low technical level of the patented invention

g. Lack of interest from potential licenses

h. Lack of capital for starting a new firm based on the technology

i. The firm has not been able to develop any application technologies for this basic invention

j. The line of business for this invention has been downsized

$\mathrm{k}$. The new line of business based on the invention has not been successful

1. The development of complementary technology in other technology fields is delayed

m. Other

n. Don't know 